\title{
Validation of in situ Measurements of Atmospheric Nitrous Acid Using Incoherent Broadband Cavity-enhanced Absorption Spectroscopy
}

\author{
Yoshihiro NAKASHIMA ${ }^{* \dagger}$ and Yasuhiro SADANAGA** \\ *Department of Environmental Science on Biosphere, Graduate School of Agriculture, Tokyo University of \\ Agriculture and Technology, 3-5-8 Saiwai-cho, Fuchu, Tokyo 183-8509, Japan \\ **Department of Applied Chemistry, Graduate School of Engineering, Osaka Prefecture University, 1-1 Gakuen-cho, \\ Naka, Sakai, Osaka 599-8531, Japan
}

\begin{abstract}
Incoherent broadband cavity-enhanced absorption spectroscopy (IBBCEAS) is a useful technique for measuring trace gaseous species in the atmosphere. Recently, IBBCEAS was used to measure concentrations of nitrous acid (HONO) in the troposphere to resolve controversies related to its formation and loss. Here, measurements of HONO and a mixture of $\mathrm{HONO}$ and $\mathrm{NO}_{2}$ using IBBCEAS were validated by comparing them with those obtained with a NOx analyzer. Good agreement was found between these methods, given their respective experimental uncertainties. The detection limit of our IBBCEAS instrument was $0.2 \mathrm{ppbv}$, with a signal-to-noise ratio of 1 , and a 5-min integration time.
\end{abstract}

Keywords Nitrous acid, incoherent broadband cavity enhanced absorption spectroscopy (IBBCEAS), in situ measurements

(Received September 24, 2016; Accepted November 25, 2016; Published April 10, 2017)

\section{Introduction}

Nitrous acid (HONO) is an important source of hydroxyl radical $(\mathrm{OH})$ during the daytime. Because HONO is photolyzed by near-UV light, HONO is the main OH-radical source in the early morning. ${ }^{1,2}$ The hydroxyl radical initiates the oxidation of trace species, resulting in the formation of photochemical oxidants and secondary organic aerosols. Therefore, knowledge concerning the HONO budget aids in our understanding of the photochemistry of the troposphere.

Determining the sources of HONO has been one of the main issues concerning its photochemistry. The formation processes of $\mathrm{HONO}$ by the heterogeneous reaction of $\mathrm{NO}_{2}$ with $\mathrm{H}_{2} \mathrm{O}$ on moist surfaces were suggested: ${ }^{3}$

$$
\begin{aligned}
& \mathrm{NO}_{2}+\mathrm{NO}+\mathrm{H}_{2} \mathrm{O} \longrightarrow 2 \mathrm{HONO}, \\
& 2 \mathrm{NO}_{2}+\mathrm{H}_{2} \mathrm{O} \longrightarrow \mathrm{HONO}+\mathrm{HNO}_{3} .
\end{aligned}
$$

In addition, various primary emission sources ${ }^{4-6}$ and secondary formation processes ${ }^{7-10}$ of HONO have also been reported. However, recent field observations show a discrepancy between the measurements and modelling of daytime HONO concentrations. ${ }^{11}$ This indicates that our understanding of the HONO budget is incomplete, and further field and laboratory studies are clearly required.

There are some ambient measurement methods for HONO subdivided into two types: direct and indirect methods. For an

† To whom correspondence should be addressed.

E-mail: nakasima@cc.tuat.ac.jp indirect measurement of HONO, a long-path absorption photometer (LOPAP) technique has recently been developed ${ }^{12,13}$ based on wet chemistry. Gaseous HONO is absorbed into a liquid phase and then converted to an azo dye. The LOPAP has high sensitivity, good spatial and time resolution, with a low detection limit of 3-6 pptv and a response time of $4 \mathrm{~min}$. However, it has potential chemical interference from other trace species (e.g., $\mathrm{NOx}, \mathrm{O}_{3}, \mathrm{HNO}_{3}$ ) in ambient air. Another method for the measurement of HONO using wet chemistry is the airdragged aqua-membrane denuder. ${ }^{14}$ HONO is absorbed in an aqueous solution using a denuder, where it reacts with 2 , 3-diaminonaphthalene to form 1-naphthotriazol, which can be measured using its fluorescence. Its detection limit is $8.1 \mathrm{pptv}$ in $2 \mathrm{~min}$. In this technique, the chemical interference from trace species is negligible. ${ }^{14}$ These indirect methods can detect HONO with high sensitivity, as well as high spatial and temporal resolution. However, they depend on frequent maintenance, such as the replacement of solutions, because they are wet chemical techniques. In contrast, differential optical absorption spectroscopy (DOAS) is a direct method used for simultaneous ambient measurements of various trace species, including HONO. ${ }^{15,16}$ Optical absorption of HONO is observed around the UV light region $(300-400 \mathrm{~nm})$, having a narrow band structure. Using this optical property of HONO, DOAS can distinguish its absorption spectrum from other trace species, such as $\mathrm{NO}_{2}$ and formaldehyde, and determine the concentrations of HONO with a low detection limit. However, DOAS has a low spatial resolution because of its necessarily long optical path length. Laser cavity ring-down spectroscopy (LCRDS) is an optical absorption spectroscopic technique that uses a laser; it has also been employed for ambient measurements of atmospheric trace species, such as $\mathrm{NO}_{2}$ and $\mathrm{NO}_{3}$ radical. ${ }^{17,18}$ 


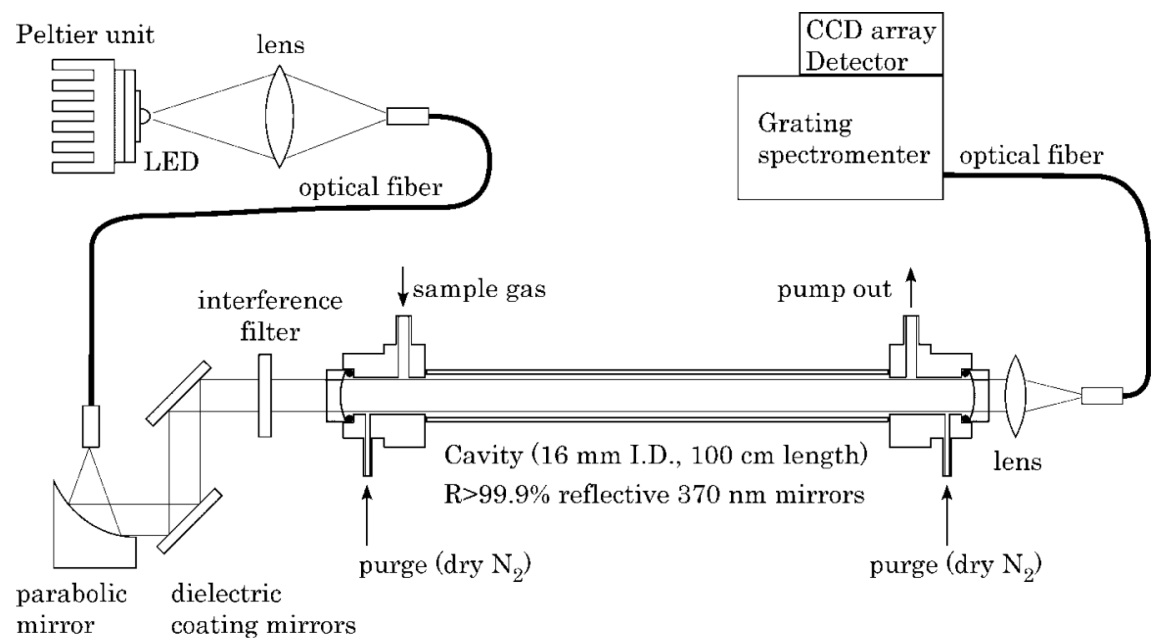

Fig. 1 Schematic diagram of our incoherent broad-band cavity-enhanced absorption spectrometer. CCD, charge-coupled device; I.D., internal diameter.

Recently, incoherent broadband cavity-enhanced absorption spectroscopy (IBBCEAS) has been used to measure trace species. IBBCEAS is one of the optical absorption techniques having high spatial resolution. Due to the direct measurement technique, it can avoid chemical interference, like wet chemistry, and interference caused by light absorption from non-target trace species, similar to DOAS. Moreover, IBBCEAS can achieve better detection limits through customizing optical parts, and using a stable light source, and a high sensitivity (or low noise) detector. Importantly, the stability of the light source improved dramatically with the use of high-power LEDs, ${ }^{19}$ which are easier and safer to handle than other light sources, such as lasers. IBBCEAS has been used in many studies to measure ambient concentrations of trace species. ${ }^{20-22}$ In particular, for $\mathrm{NO}_{2}$ measurements, comparisons of various techniques with IBBCEAS results have been carried out, validating IBBCEAS measurements. ${ }^{23}$

IBBCEAS measures $\mathrm{HONO}$ and $\mathrm{NO}_{2}$ simultaneously, in essentially the same sample air, which offers a great advantage to researchers. As described above, HONO is closely related to NOx in the atmosphere, through reactions (1) and (2), which outlines one of the most important secondary formation processes of HONO. A comparison of IBBCEAS and LOPAP measurements was carried out in ambient air. ${ }^{22}$ Because LOPAP is an indirect measurement technique and has some potential interferences, it is necessary to validate the accuracy of IBBCEAS for gas-phase $\mathrm{HONO}$ and $\mathrm{NO}_{2}$ mixtures by comparing some techniques without wet chemistry using standard gases. In this study, simultaneous measurements of HONO using IBBCEAS and a chemiluminescence NOx analyzer with a molybdenum reducing catalyst (Mo converter) was carried out. Because the NOx analyzer with a Mo converter can measure HONO concentrations in the absence of any other nitrogen compounds, ${ }^{14,24}$ comparisons between these two different measurement techniques can be used to validate measurements of HONO using IBBCEAS. Because $\mathrm{NO}_{2}$ and HONO coexist in ambient air, the simultaneous measurement of the mixtures of $\mathrm{HONO}$ and $\mathrm{NO}_{2}$ gases was undertaken. The concentration of $\mathrm{NO}_{2}$ was monitored using cavity attenuated phase shift spectroscopy (CAPS) to obtain accurate concentrations of $\mathrm{NO}_{2}$ in the mixture, given that the NOx analyzer can only measure the sum of $\mathrm{NO}_{2}$ and $\mathrm{HONO}$.

\section{Experimental}

Incoherent broadband cavity-enhanced absorption spectrometer A schematic diagram of our incoherent broadband cavityenhanced absorption spectrometer is shown in Fig. 1. Our instrument is similar to earlier models, ${ }^{20-22}$ and consists of a light source, with optics for introducing light into a cavity, and a spectrometer with a charge-coupled device (CCD) array detector. A high-power UV LED (M365D1; Thorabs Inc., NJ, USA) was employed as a light source, with an optical power of $360 \mathrm{~mW}$, a center wavelength of $365 \mathrm{~nm}$, and full width at half maximum of $7.5 \mathrm{~nm}$. The light intensity of the LED was controlled by a DC power supply, and ambient temperature was kept at $273 \mathrm{~K}$ by a Peltier unit so as to avoid any fluctuation of its center wavelength. UV light was focused by a quartz aspherical lens having a focal length of $33 \mathrm{~mm}$ into a multimode optical fiber, with a $300-\mu \mathrm{m}$ core diameter and $10-\mathrm{m}$ length. The output of the optical fiber was coupled with an aluminum parabolic mirror to collimate the UV light into a beam with a diameter of around $10 \mathrm{~mm}$. Collimated UV light was introduced into the cavity by reflecting it off two coated dielectric mirrors (Los Gatos Research, CA, USA). Before the UV light was introduced to the cavity, an interference filter (YIF-340; Sigma Koki, Japan) was employed to remove any unnecessary wavelength region of light. The UV light transmitted through the cavity was focused by a quartz lens with a focal length of $50 \mathrm{~mm}$ so as to introduce it to another multimode optical fiber (300- $\mu \mathrm{m}$ core diameter and 10-m length) connected with the spectrometer (Andor SR163, Oxford Instruments, UK) having a $-60^{\circ} \mathrm{C}$ cooled $1024 \times 127$ pixel $\mathrm{CCD}$ array detector (Andor DU401A-BV). In the spectrometer, a $25-\mu \mathrm{m}$ fixed-width slit and a 1200 groove/mm grating (500 nm blaze) were deployed. The spectrum resolution was $\sim 0.5 \mathrm{~nm}$. The exposure time of the CCD detector was set at $20 \mathrm{~s}$. Measurements of the spectrum were carried out every 15 times and averaged.

The optical cavity consisted of two highly reflective mirrors with mirror mounts (Los Gatos Research). The mirror mounts were connected to two polytetrafluoroethylene (PTFE) blocks, with 1/4-inch outer diameter inlet and outlet tubes made of perfluoroalkoxy alkane (PFA), and a 1-m length of PFA tube. To avoid polluting the mirrors, $500 \mathrm{sccm}$ (standard cubic centimeters per minute) of pure nitrogen gas, controlled by a 


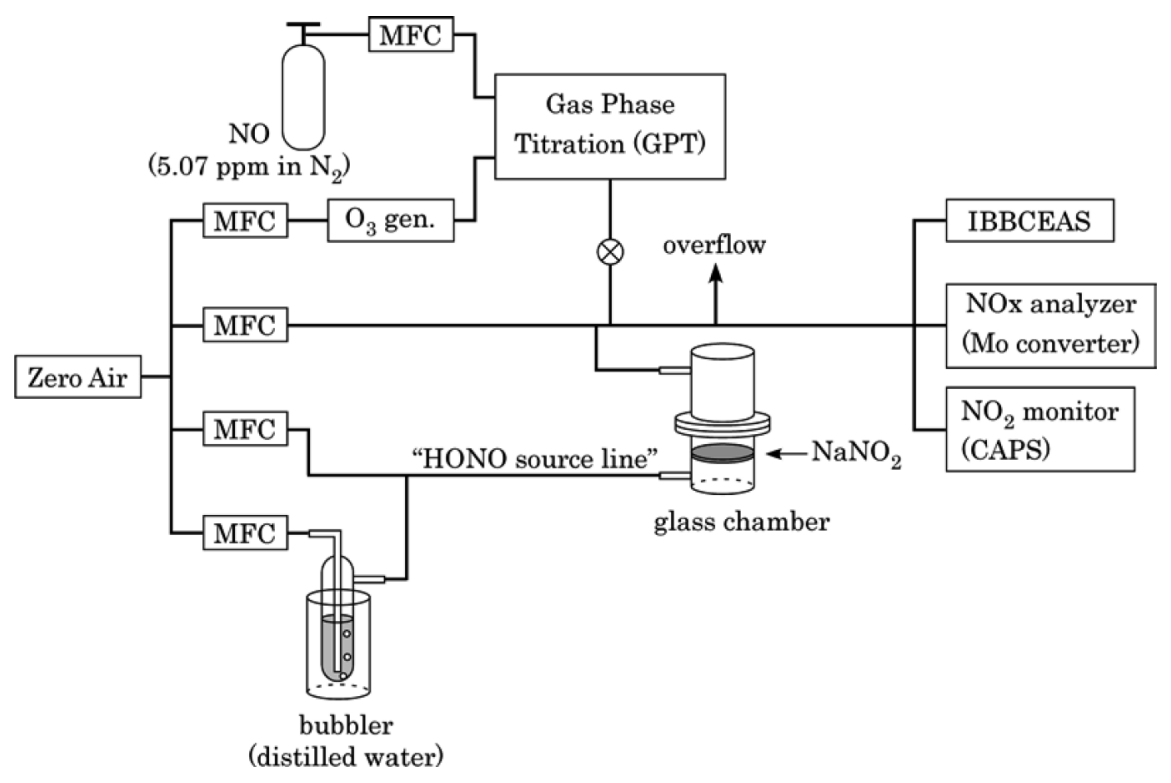

Fig. 2 Block diagram showing the gas-flow system of $\mathrm{HONO}$ and $\mathrm{NO}_{2}$ to the measuring instruments. MFC stands for mass flow controller. IBBCEAS, incoherent broad-band cavity-enhanced absorption spectroscopy; CAPS, cavity attenuated phase-shift spectroscopy.

mass flow controller (Kofloc Model 3660; Kojima Instruments Inc., Japan), was introduced along the sides of the mirrors as a purge gas. Because aerosol-free gas was used in our study, there was no need for an aerosol cut filter. Airflow from the outlet of the cavity was evacuated using a diaphragm pump (DA-60S; ULVAC Technologies, MA, USA) through a flowcontrol valve, using a mass flow sensor (Kofloc Model 3810S). The airflow rate was measured to be approximately 10 SLM.

\section{Simultaneous measurements}

The measurements of HONO and a mixture of HONO and $\mathrm{NO}_{2}$ using IBBCEAS were validated using an NOx analyzer with a Mo converter based on an $\mathrm{NO}-\mathrm{O}_{3}$ chemiluminescence method (Model 42i-TL; Thermo Fisher Scientific, MA, USA) and an $\mathrm{NO}_{2}$ monitor (CAPS- $\mathrm{NO}_{2}$; Shoreline Science Research Inc., Japan). Figure 2 shows the experimental apparatus used for validating our IBBCEAS instrument. Zero air was passed through the $\mathrm{HONO}$ (and $\mathrm{NO}_{2}$ ) source to generate a standard $\mathrm{HONO}$ (or $\mathrm{HONO}+\mathrm{NO}_{2}$ ) gas. This standard gas was diluted by additional zero air. The diluted standard gas was introduced into our spectrometer, as well as the NOx analyzer, and the CAPS- $\mathrm{NO}_{2}$ analyzer. The NOx analyzer measured the sum of the $\mathrm{HONO}$ and $\mathrm{NO}_{2}$ concentrations. The detection limit of the NOx analyzer was measured using a standard deviation of the blank signals $(\sigma)$ and estimated to be $42 \mathrm{pptv}$ for a 1-min integration time $(3 \sigma)$. To measure $\mathrm{NO}_{2}$ independently, an $\mathrm{NO}_{2}$ monitor based on a CAPS method ${ }^{25}$ was employed. The detection limit of $\mathrm{NO}_{2}$ by the CAPS- $\mathrm{NO}_{2}$ analyzer was estimated to be $17 \mathrm{pptv}$ for a 1 -min integration time $(3 \sigma)$. The HONO concentration for the standard gas can be obtained using the following equation:

$$
[\mathrm{HONO}]=C_{\mathrm{Mo}}-C_{\mathrm{NO} 2},
$$

where $C_{\mathrm{MO}}$ and $C_{\mathrm{NO} 2}$ are the concentrations from the NOx analyzer and the $\mathrm{NO}_{2}$ monitor, respectively.

The three instruments were connected by PFA tubes and PTFE connectors to the main flow line. The flow rate of the NOx analyzer was so small ( 0.5 SLM) compared with other instruments, especially the IBBCEAS, that we made the PFA tube connecting the inlet of NOx analyzer to the main flow line be as short as possible. Our spectrometer measures the concentrations of $\mathrm{HONO}$ and $\mathrm{NO}_{2}$ simultaneously, around the 360-nm wavelength region.

\section{Preparation of gaseous $\mathrm{HONO}$ and $\mathrm{NO}_{2}$}

Gaseous HONO is usually generated using the heterogeneous reaction of $\mathrm{NaNO}_{2}$ with a humidified $\mathrm{HCl}$ gas. ${ }^{24}$ However, the desired concentration of $\mathrm{HONO}$ was produced by the reaction of $\mathrm{NaNO}_{2}$ with water vapor ${ }^{26}$ in this study. Specifically, humidified zero air was introduced into a glass chamber $(7.5-\mathrm{cm}$ inner diameter and 24-cm length). A glass filter was set inside this chamber (see Fig. 2) and granular $\mathrm{NaNO}_{2}$ (>98.5\%; Wako Pure Chemical Industries Ltd., Japan) was put on the glass filter. The humidified zero air reacted with $\mathrm{NaNO}_{2}$ in the glass chamber to generate HONO. The HONO concentration was controlled by adjusting the humidity of the zero air. The humidity was adjusted by the following procedure. A part of the zero air flow through the HONO source line (see Fig. 2) was divided into a water bubbler to be bubbled and added back to the main flow, and then the flow was supplied into the glass chamber. The deliquescence of $\mathrm{NaNO}_{2}$ was not observed, although the relative humidity was not monitored. The HONO generated was diluted by additional zero air without purification. The $\mathrm{NO}_{2}$ concentrations in the $\mathrm{HONO}$ standard gas were confirmed to be below the detection limit of the CAPS- $\mathrm{NO}_{2}$ analyzer.

$\mathrm{NO}_{2}$ was generated using a gas-phase titration method. ${ }^{27}$ Briefly, ozone was added to a 5.07-ppmv $\mathrm{NO} / \mathrm{N}_{2}$ standard gas (Taiyo Nippon Sanso, Japan) to oxidize NO to $\mathrm{NO}_{2}$, and then this $\mathrm{NO} / \mathrm{NO}_{2}$ mixture was diluted with zero air. The $\mathrm{NO}_{2}$ generation was carried out using a commercially available dynamic gas dilution system (Model 103G; Nippon Thermo Co., Ltd., Japan) in this study.

\section{Retrieval method}

The detailed measurement principles for trace gas concentrations from IBBCEAS have been published elsewhere. ${ }^{28}$ 
In this section, the derivation method for trace gas concentrations is briefly described. Extinction related to the light absorption of a trace species, denoted by $\alpha_{\text {abs }}(\lambda)$, is derived from the following equation:

$$
\begin{aligned}
\alpha_{\mathrm{abs}}(\lambda)=\left(\frac{1-R(\lambda)}{L}+\alpha_{\text {Ray }}(\lambda)\right) & \left(\frac{I_{0}(\lambda)-I(\lambda)}{I(\lambda)}\right)= \\
& \left(\frac{1}{L^{\prime}(\lambda)}+\alpha_{\text {Ray }}(\lambda)\right) \frac{\Delta I(\lambda)}{I(\lambda)},
\end{aligned}
$$

where $I_{0}(\lambda)$ and $I(\lambda)$ are the light intensity transmitted through the cavity in the absence and presence of the trace species, respectively; $R(\lambda)$ is the mirror reflectivity; and $L$ is the distance between the two mirrors. The symbol $\alpha_{\text {Ray }}(\lambda)$ was used to denote extinction related to Rayleigh scattering in air in this study. Because of the small variation in the cross-section of the Rayleigh scattering, compared with the wavelength region and the narrow analysis range $(15 \mathrm{~nm})$ of the spectrum, the wavelength dependence of $\alpha_{\text {Ray }}(\lambda)$ was negligible. A value of $\alpha_{\text {Ray }}(\lambda) 7 \times 10^{-7} \mathrm{~cm}^{-1}$ at $1 \mathrm{~atm}$ and $360 \mathrm{~nm}$ was applied in our study. ${ }^{22}$ To solve Eq. (4), it is necessary to obtain the effective path length, $L^{\prime}(\lambda)$, related to the mirror reflectivity. This allows us to determine the concentration of the trace species. Here, the effective path length was derived using the following procedure. First, simultaneous measurements of standard $\mathrm{NO}_{2}$ gas using the IBBCEAS and CAPS- $\mathrm{NO}_{2}$ methods were carried out. The absorption spectrum of $\mathrm{NO}_{2}$ from IBBCEAS was derived for the observed spectral range of $350-395 \mathrm{~nm}$. Second, the effective path length was determined based on retrieval for every $5 \mathrm{~nm}$ in the observed spectrum. For our retrieval of $\mathrm{NO}_{2}$, high-resolution data for the absorption cross-section ${ }^{29}$ were employed. Finally, this effective path length was fitted with a 3rd-order polynomial function for the wavelength. The effective path length for a wavelength of $367 \mathrm{~nm}$ was estimated to be $4.6 \mathrm{~km}$. This corresponds to 0.99985 of the mirror reflectivity for $100 \mathrm{~cm}$ of the path length, and $7 \times 10^{-7} \mathrm{~cm}^{-1}$ of the Rayleigh scattering. A previously reported absorption cross-section for HONO was used. ${ }^{30}$ The uncertainty in the concentration of HONO is estimated to be around $6 \%$, based on the uncertainties for the cross-section for HONO (5\%), the effective path length $(4 \%)$, and $\Delta I(\lambda) / I(\lambda)$ (i.e., $0.05 \%$ for a signal to noise ratio of 1 ).

The concentrations of HONO and a mixture of HONO and $\mathrm{NO}_{2}$ were retrieved using DOASIS software developed by the Institute of Environmental Physics at Heidelberg University, Germany, ${ }^{31}$ for the wavelength range of $360-375 \mathrm{~nm}$. The fitting model function of DOASIS for the absorption spectrum, $I(\lambda)$, was given by:

$$
I(\lambda)=\exp \left(\sum \sigma_{\mathrm{i}}[n]_{\mathrm{i}}\left(s_{\mathrm{i}}+t_{\mathrm{i}} \lambda\right)+P(\lambda)\right)+O(\lambda),
$$

where $\sigma_{\mathrm{i}}$ and $[n]_{\mathrm{i}}$ are the cross section and the number density for related trace species, respectively. The coefficients $s_{\mathrm{i}}$ and $t_{\mathrm{i}}$ are the shift and squeeze parameters for each cross section, respectively. The functions $O(\lambda)$ and $P(\lambda)$ denote the additional polynomial function to modify the effect of the fluctuation of the baseline, and a polynomial function to modify some weak absorption or scattering. Finally, our measurements showed weak absorption for the $\mathrm{O}_{2}$ dimer. ${ }^{32}$ However, the absorption intensity of the $\mathrm{O}_{2}$ dimer was so weak that no band structure was observed on our spectra; thus, their contribution to absorption was not considered in this study.

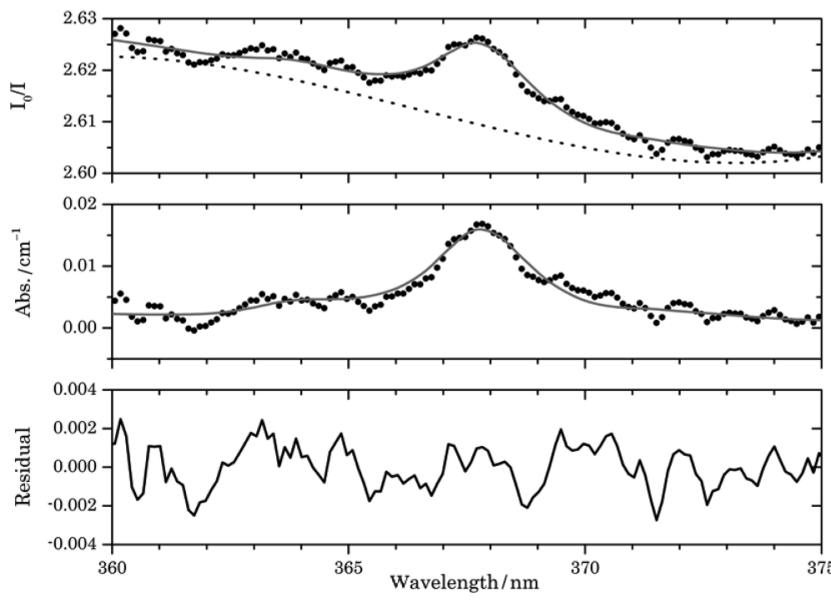

Fig. 3 Example analysis of the concentration of $\mathrm{HONO}(1.71 \pm 0.04$ ppbv) using DOASIS software. The exposure time of the CCD detector was set to $20 \mathrm{~s}$. The measurements of the spectrum were carried out every 15 times and averaged. The top panel shows the observed (filled circles) and fitted (gray curve) spectra, respectively. $I_{0} / I$ is the ratio of the light intensity transmitted through the cavity in the absence and presence of HONO. The baseline, derived from the retrieval of the spectrum by DOASIS software, is shown by a dotted line. Subtraction of the baseline from the observed spectrum and a scaled cross-section for HONO are represented by filled circles and a gray curve in the middle panel, respectively. The bottom panel gives the residual spectrum.

\section{Results and Discussion}

\section{Validation of HONO measurements}

An example of the spectrum of HONO measured by the IBBCEAS and its retrieval using DOASIS software is shown in Fig. 3. In the top panel of Fig. 3, observed and fitted spectra are indicated by filled circles and a grey curve, respectively. A fluctuation of the baseline, indicated by the dotted line, was observed, presumably causing by a slight fluctuation of the intensity of LED or an instability of the cavity. In this study, this fluctuation was modified by the polynomial function, $O(\lambda)$, in Eq. (5). The HONO concentration was estimated to be $1.71 \pm 0.04 \mathrm{ppbv}(1 \sigma)$. The relative standard deviation of the concentration of HONO for all measurements was $\sim 5 \%$. The bottom panel of Fig. 3 shows the residual spectrum. The average and $1 \sigma$ standard deviation of the residual were $6.4 \times 10^{-6}$ and $1.1 \times 10^{-3}$, respectively.

The correlation between HONO measurements from IBBCEAS and chemiluminescence NOx analyzer is shown in Fig. 4. The slope of the regression line is $1.11 \pm 0.07$, and its intercept is $0.2 \pm 0.2 \mathrm{ppbv}(1 \sigma)$, giving an $R^{2}$ value of 0.98 . The main uncertainty in measurements of the NOx analyzer results from its NO calibration $( \pm 10 \%)$. The uncertainty in IBBCEAS is $\pm 6 \%$, as outlined above. Thus, the HONO concentrations measured using IBBCEAS were in good agreement with those of the NOx analyzer, by taking into account their respective uncertainties.

Simultaneous measurements of $\mathrm{HONO}$ and $\mathrm{NO}_{2}$ were also carried out. An example of a spectrum of the mixture of HONO and $\mathrm{NO}_{2}$ obtained from IBBCEAS and its retrieval is shown in Fig. 5. The top panel of Fig. 5 shows the observed (filled circles) and fitted spectra (grey curve), respectively. The second and third panels of Fig. 5 are $\mathrm{NO}_{2}$ and HONO spectra extracted from the observed spectrum in the top panel, respectively. 


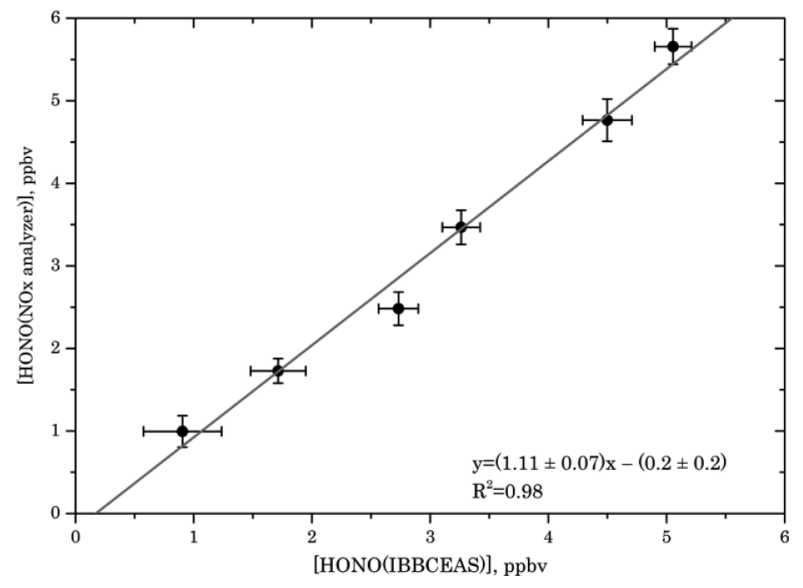

Fig. 4 Correlation between measurements of HONO from incoherent broad-band cavity-enhanced absorption spectroscopy (IBBCEAS) and the NOx analyzer. The gray line is the regression line. Error bars for each data point are the $1 \sigma$ standard deviation for each instrument. Their slope, $y$-intercept, and $1 \sigma$ error are also shown.

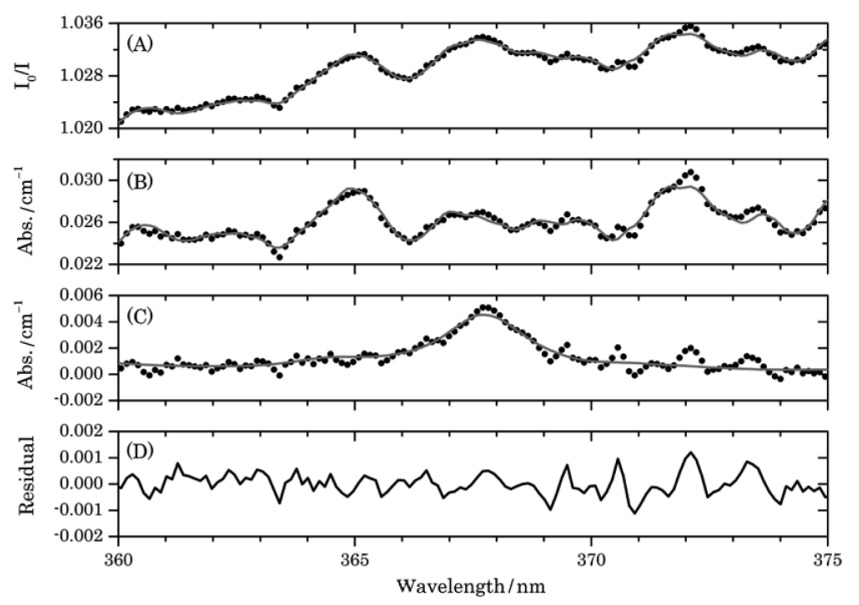

Fig. 5 Example of our estimation of the concentration of HONO $(1.06 \pm 0.06 \mathrm{ppbv})$ and $\mathrm{NO}_{2}(3.99 \pm 0.17 \mathrm{ppbv})$ using DOASIS software. Exposure time of the CCD detector was set to $20 \mathrm{~s}$. The measurements of the spectrum were carried out every 15 times and averaged. Panel (A) shows observed (filled circles) and fitted (gray curve) spectra, respectively. $I_{0} / I$ is the ratio of light intensity transmitted through the cavity in the absence and presence of HONO. Extracted spectra of $\mathrm{NO}_{2}$ (panel (B)) and $\mathrm{HONO}$ (panel (C)) are represented by filled circles, respectively. Scaled cross-sections for $\mathrm{NO}_{2}$ and $\mathrm{HONO}$ are shown by each panel, respectively. Panel (D) is the residual spectrum.

The bottom panel of Fig. 5 is the residual spectrum. The average and the $1 \sigma$ standard deviation of the residual were $1.8 \times 10^{-6}$ and $4.1 \times 10^{-4}$, respectively. The concentrations and $1 \sigma$ standard deviation of $\mathrm{HONO}$ and $\mathrm{NO}_{2}$ were estimated to be $1.04 \pm 0.06$ and $3.99 \pm 0.17 \mathrm{ppbv}$, respectively. The relative standard deviations of the concentrations of $\mathrm{HONO}$ and $\mathrm{NO}_{2}$ were $\sim 3$ and $\sim 4 \%$, respectively.

The correlation between measurements of HONO using the NOx analyzer is shown in Fig. 6. The concentration of $\mathrm{NO}_{2}$ was fixed to around $4.4 \mathrm{ppbv}$, while that of HONO was varied from sub-ppbv to 7 ppbv levels. The regression line has a slope of $0.97 \pm 0.03$ and an intercept of $0.3 \pm 0.1 \mathrm{ppbv}$, with an $R^{2}$ value of 0.99 . Considering the main uncertainty in

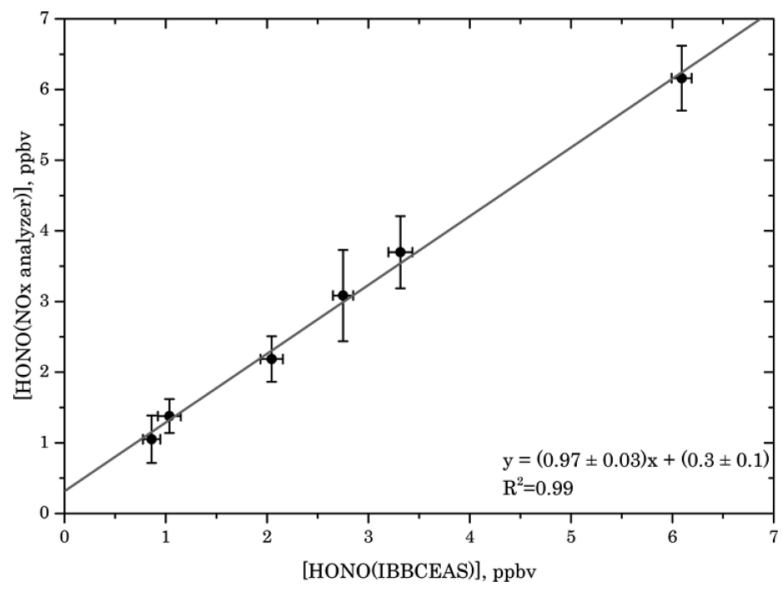

Fig. 6 Correlation between measurements for a mixture of HONO and $\mathrm{NO}_{2}$ from incoherent broad-band cavity-enhanced absorption spectroscopy (IBBCEAS) and the NOx analyzer. The concentration of $\mathrm{NO}_{2}$ was $4.41 \pm 0.05$ ppbv measured by cavity attenuated phase shift spectroscopy, CAPS. The gray line is the regression line. The error bars for each data point are the $1 \sigma$ standard deviation for each instrument. Their slope, $y$-intercept and their $1 \sigma$ error are also shown.
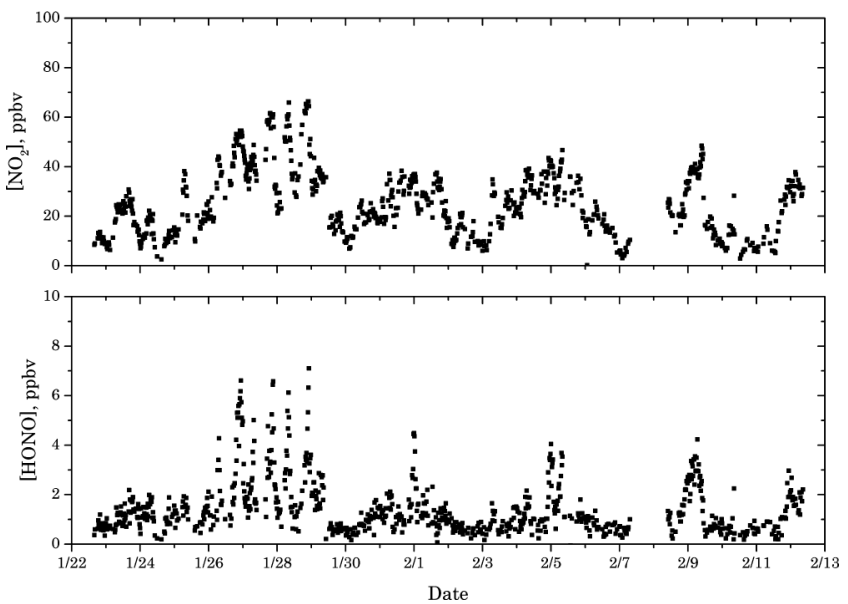

Fig. 7 The example of the ambient measurements of $\mathrm{NO}_{2}$ and HONO in an urban area in Tokyo during the winter season (January 22nd - February 12th). The repetition times of the measurements were set to $4 \mathrm{~min}$.

measurements of the NOx analyzer and CAPS- $\mathrm{NO}_{2}$ resulting from NO calibration and IBBCEAS, HONO concentrations measured using IBBCEAS were in excellent agreement with those of the NOx analyzer, even in the presence of $\mathrm{NO}_{2}$. The average concentration of $\mathrm{NO}_{2}$ in the $\mathrm{HONO}+\mathrm{NO}_{2}$ mixture was measured to be $4.16 \pm 0.20$ ppbv using IBBCEAS, which is in consistent with measurements from CAPS (4.41 $\pm 0.05 \mathrm{ppbv})$, i.e., within $1 \sigma$ standard deviation.

\section{Sensitivity of HONO measurements}

Applying the uncertainty measure of $\Delta I(\lambda) / I(\lambda)$ to the minimum absorption difference in the observed spectral range, the detection limit for our spectrometer was estimated to be 0.2 ppbv, using a $2 \sigma$ standard deviation, and the $300 \mathrm{~s}$ of integration time in Eq. (4). The detection limit for HONO for our IBBCEAS instrument compared with the previous study 22 has been slightly improved. 


\section{Examples of the in situ measurements of HONO}

As our next step, we have made two plans: ambient measurements of the concentrations of HONO during the season, and an estimation of the emission factor or flux of HONO from some sources.

For the first plan, we tried to measure the ambient concentration of HONO at an urban site of Tokyo during the winter season in 2016. The measurement site, Tokyo Metropolitan Research Institute for Environmental Protection (TMRIEP), is located in urban central Tokyo. The results of the measurements of HONO at TMRIEP during the winter season (January 22nd - February 12th) in 2016 are shown in Fig. 7. During the measurement period, it was not necessary to align the cavity in order to modify the sensitivity caused by some troublesome problems (pollution of the mirrors by aerosol, distortion of the alignment etc.). The average of the concentrations of $\mathrm{NO}_{2}$ and $\mathrm{HONO}$ were $26.2 \pm 13.6$ and $1.5 \pm 1.1 \mathrm{ppbv}$, respectively. Simultaneous measurements of ambient $\mathrm{NO}_{2}$ were carried out by the CAPS$\mathrm{NO}_{2}$ analyzer. Good agreement was confirmed by the correlation of the concentration of $\mathrm{NO}_{2}$ from IBBCEAS and CAPS-NO with the slope of the regression line being $1.03 \pm 0.01$, and the $R^{2}$ value was 0.94 . The concentration variation of HONO was similar with that of $\mathrm{NO}_{2}$, and the moderate correlation between the concentration of $\mathrm{HONO}$ and $\mathrm{NO}_{2}\left(R^{2}=0.6\right)$ was observed. Analysis of the correlation between the components of aerosol and HONO were performed. In the future, we will continue to conduct the ambient measurements under different conditions for the season and location such as suburban or rural site.

For the second plan, the emission factors (EFs) of HONO from gasoline vehicular exhaust have been estimated. ${ }^{33}$ Measurements of HONO and other trace species concentrations such as CO, NOx, total hydrocarbons (THCs) in gasoline exhaust were conducted at the National Institute for Environmental Studies (NIES) in Tsukuba, Japan. For these measurements, six different passenger vehicles made by a Japanese company, and in compliance with the 2005 Japanese emission control standard, were studied. As a result, concerning HONO we found that the EFs were different from the vehicle's specifications and under different driving cycles. The annual HONO emissions in Japan were estimated using the calculated EFs and other statistical data. In the future, determinations of the EFs for HONO from diesel vehicle or old gasoline vehicle will be continued.

\section{Acknowledgements}

This work was supported by JSPS KAKENHI Grant-in-Aid for Young Scientists (B) (No. 26740005). We thank to Kou Arima for helping with the development of our IBBCEAS instrument.

\section{References}

1. B. Alicke, U. Platt, and J. Stutz, J. Geophys. Res., 2002, 107, 8196.

2. B. Vogel, H. Vogel, J. Kleffmann, and R. Kurtenbach, Atmos. Environ., 2003, 37, 2957.

3. J. G. Calvert, G. Yarwood, and A. M. Dunker, Res. Chem. Intermediat., 1994, 20, 463.

4. H. Su, Y. Cheng, R. Oswald, T. Behrendt, I. Trebs, F. X. Meixner, M. O. Andreae, P. Cheng, Y. Zhang, and U. Pöschl, Science, 2011, 333, 1616.

5. H. Beine, A. J. Colussi1, A. Amoroso, G. Esposito, M. Montagnoli, and M. R. Hoffmann, Environ. Res. Lett., 2008, 3, 0450.

6. R. Kurtenbach, K. H. Becker, J. A. G. Gomes, J. Kleffmann,
J. C. Lörzer, M. Spittler, P. Wiesen, R. Ackermann, A. Geyer, and U. Platt, Atmos. Environ., 2001, 35, 3385.

7. D. Amedro, A. E. Parker, C. Schoemaecker, and C. Fittschen, Chem. Phys. Lett., 2011, 513, 12.

8. X. L. Zhou, H. L. Gao, Y. He, G. Huang, S. B. Bertman, K. Civerolo, and J. Schwab, Geophys. Res. Lett., 2003, 30, 2217.

9. F. Rohrer, B. Bohn, T. Brauers, D. Brüning, F. J. Johnen, A. Wahner, and J. Kleffmann, Atmos. Chem. Phys., 2005, 5, 2189.

10. C. George, R. S. Sterkowski, J. Kleffmann, K. Stemmler, and M. Ammann, Faraday Discuss., 2005, 130, 195.

11. B. H. Czader, B. Rappenglück, P. Percell, D. W. Byun, F. Ngan, and S. Kim, Atmos. Chem. Phys., 2012, 12, 6939.

12. J. Heland, J. Kleffmann, R. Kurtenbach, and P. Wiesen, Environ. Sci. Technol., 2001, 35, 3207.

13. J. Kleffmann, Chem. Phys. Chem., 2007, 8, 1137.

14. N. Takenaka, H. Terada, Y. Oro, M. Hiroi, H. Yoshikawa, K. Okitsu, and H. Bandow, Analyst, 2004, 129, 1130.

15. D. Perner and U. Platt, Geophys. Res. Lett., 1979, 6, 917.

16. B. Alicke, A. Geyer, A. Hofzumahaus, F. Holland, S. Konrad, H. W. Patz, J. Schafer, J. Stutz, A. V. Thomas, and U. Platt, J. Geophys. Res., 2003, 108, 8247.

17. H. D. Osthoff, S. S. Brown, B. R. Thomas, T. J. Fortin, B. M. Lerner, E. J. Williams, A. Pettersson, T. Baynard, W. P. Dube, S. J. Ciciora, and A. R. Ravishankara, J. Geophys. Res., 2006, 111, D12305.

18. S. S. Brown, W. P. Dube, H. D. Osthoff, D. E. Wolfe, W. M. Angevine, and A. R. Ravishankara, Atmos. Chem. Phys., 2007, 7, 139.

19. T. Wu, W. Zhao, W. Chen, W. Zhang, and X. Gao, Appl. Phys. B, 2009, 94, 85.

20. J. M. Langridge, S. M. Ball, and R. L. Jones, Analyst, 2006, $131,916$.

21. J. M. Langridge, S. M. Ball, A. J. L. Shillings, and R. L. Jones, Rev. Sci. Instrum., 2008, 79, 123110.

22. T. Wu, Q. Zha, W. Chen, Z. Xu, T. Wang, and X. He, Atmos. Environ., 2014, 95, 544.

23. H. Fuchs, S. M. Ball, B. Bohn, T. Brauers, R. C. Cohen, H. P. Dorn, W. P. Dube, J. L. Fry, R. Haseler, U. Heitmann, R. L. Jones, J. Kleffmann, T. F. Mentel, P. Müsgen, F. Rohrer, A. W. Rollins, A. A. Ruth, A. Kinedler-Scharr, E. Schlosser, A. J. L. Shillings, R. Tillmann, R. M. Varma, D. S. Venables, G. V. Tapia, A. Wahner, R.Wegener, P. J. Wooldridge, and S. S. Brown, Atmos. Meas. Tech., 2010, 3, 21.

24. A. Febo, C. Perrino, M. Gherardi, and R. Sparapani, Environ. Sci. Technol., 1995, 29, 2390.

25. P. L. Kebabian, E. C. Wood, S. C. Herndon, and A. Freedman, Environ. Sci. Technol., 2008, 42, 6040.

26. C. Afif, C. Jambert, V. Michoud, A. Colomb, G. Eyglunent, A. Borbon, V. Daële, J. Doussin, and P. Perros, J. Environ. Sci., 2016, 40, 105.

27. Y. Sadanaga, K. Suzuki, T. Yoshimoto, and H. Bandow, Rev. Sci. Instrum., 2014, 85, 064101.

28. R. M. Varma, D. S. Venables, A. A. Ruth, U. Heitmann, E. Schlosser, and S. Dixneuf, Appl. Opt., 2009, 48, B159.

29. J. P. Burrows, A. Dehn, B. Deters, S. Himmelmann, A. Richter, S. Voigt, and J. Orphal, J. Quant. Spectrosc. Radiat. Transf., 1998, 60, 1025.

30. J. Stutz, E. S. Kim, U. Platt, P. Bruno, C. Perrino, and A. Febo, J. Geophys. Res., 2000, 105, 14585.

31. https://doasis.iup.uni-heidelberg.de/bugtracker/projects/doasis/ index.php/.

32. G. D. Greenblatt, J. J. Orlando, J. B. Burkholder, and A. R. Ravishankara, J. Geophys. Res., 1990, 95, 18577.

33. Y. Nakashima and Y. Kajii, Sci. Tot. Environ., 2017, 575, 287. 